\title{
INDICAÇÕES E LIMITAÇÕES DOS DIFERENTES DETERGENTES UTILIZADOS NO PROCESSAMENTO DE PRODUTOS PARA A SAÚDE
}

\author{
Indications and limitations of different detergents used in the processing of health products
} Indicaciones y limitaciones de los detergentes diferentes utilizados en el procesamiento para la salud

\author{
Adriana Cristina de Oliveira', Maria Leticia Mati ${ }^{2}$
}

RESUMO: Objetivo: Identificar estudos que abordem indicações e limitações dos diferentes detergentes utilizados no processamento de produtos para a saúde. Método: Revisão integrativa que incluiu publicações presentes nas bases de dados Scientific Eletronic Library Online, Science Direct, Scopus, Web of Science e PubMed, no período de 2000 a 2016, nos idiomas inglês e português. Resultados: Foram identificados nove estudos. Os detergentes alcalinos apresentam boa remoção de sujidades, são indicados para uso em equipamento automatizado, adequados em processos que utilizem água dura e compatíveis com instrumentais cirúrgicos de aço inoxidável. Podem danificar o produto para a saúde e reagir com alumínio, zinco, metais não ferrosos, borracha e látex. Detergentes enzimáticos são compatíveis com diversos materiais e, devido à presença de enzimas, removem diferentes sujidades do instrumental. Conclusão: Embora os detergentes alcalino e enzimático possuam similaridades, a escolha do produto exige o conhecimento da sua ação, observando as características de uso, compatibilidade com o produto para a saúde e qualidade da água.

Palavras-chave: Serviço de limpeza. Equipamentos e provisões. Detergentes.

ABSTRACT: Objective: To identify studies that address indications and limitations of different detergents used in the processing of medical devices. Method: Integrative review that included publications in Scientific Electronic Library Online, Science Direct, Scopus, Web of Science and PubMed, from 2000 to 2016, in English and in Portuguese. Results: Nine studies were identified. Alkaline detergents remove dirt well, its use is indicated for automated equipment, and they are suitable in processes that use hard water, compatible with surgical stainless steel instruments. They may damage the medical device and react with aluminum, zinc, non-ferrous metals, rubber and latex. Enzymatic detergents are compatible with various materials and, due to the presence of enzymes, remove different types of dirt from the instrument. Conclusion: Although alkaline and enzymatic detergents present similarities, the choice of the product requires knowledge of its action, observing the characteristics of use, compatibility with the medical device and water quality. Keywords: Housekeeping. Equipment and supplies. Detergents.

RESUMEN: Objetivo: Identificar los estudios que abordan indicaciones y limitaciones de diferentes detergentes utilizados en el procesamiento de productos de salud. Método: Revisión integrada que incluye publicaciones presentes en las bases de datos Scientific Electronic Library Online, Science Direct, Scopus, Web of Science y PubMed, de 2000 a 2016, en los idiomas Inglés y Portugués. Resultados: Se identificaron nueve estudios. Los detergentes alcalinos tienen buena eliminación de impurezas, están indicados para su uso en equipos automatizados, los procedimientos adecuados utilizando agua dura compatibles e instrumental acero inoxidable quirúrgico. Pueden dañar la salud del producto, y reaccionar con aluminio, zinc, metales no ferrosos, caucho y látex. Detergentes enzimáticos son compatible con diversos materiales y, debido a la presencia de enzimas, eliminan diferentes suciedades de los instrumentales. Conclusión: Aunque detergentes alcalinos y enzimáticos presenten similitudes, la elección del producto requiere el conocimiento de su acción, observando las características de uso, compatibilidad con el producto para la salud y la calidad del agua.

Palabras clave: Servicio de limpieza. Equipos y suministros. Detergentes.

'Pós-doutora pela Universidade de Nova York - Nova York, Estados Unidos. Coordenadora do Núcleo de Estudo e Pesquisa em Infecção Relacionada ao Cuidar em Saúde (NEPIRCS) do Conselho Nacional de Desenvolvimento Científico e Tecnológico (CNPq). Professora associada do Departamento de Enfermagem Básica da Escola de Enfermagem da Universidade Federal de Minas Gerais (UFMG) - Belo Horizonte (MG), Brasil. ${ }^{2}$ Mestranda do Programa de Pós-graduação em Enfermagem da Escola de Enfermagem da UFMG - Belo Horizonte (MG), Brasil. Avenida Professor Alfredo Balena, 190 - Santa Efigênia - CEP: 30130-100, Belo Horizonte (MG), Brasil. E-mail: mleticiamati@gmail.com

Recebido: 21 nov. 2016 - Aprovado: 17 mar. 2017

DOI: $10.5327 / Z 1414-4425201700020008$ 


\section{INTRODUÇÃO}

Os produtos para a saúde (PPS) passíveis de processamento são dispositivos médicos planejados e fabricados de maneira que permitam repetidos ciclos de limpeza, preparo e desinfecção ou esterilização até que percam a sua eficácia e/ou funcionalidade ${ }^{1}$. O processamento desses itens é indicado como uma forma de maximizar os benefícios de produtos que normalmente apresentam um custo elevado para os sistemas de saúde e de minimizar os impactos ambientais causados pelos PPS à medida que a reutilização desses dispositivos reduz o volume de resíduos lançados no ambiente ${ }^{2,3}$.

A realização de uma limpeza adequada dos PPS é um determinante para a efetividade do processamento. Ela consiste na remoção física da sujidade clínica (materiais orgânicos e inorgânicos) acompanhada da redução da carga microbiana das superfícies internas (lúmen) e externas desses dispositivos utilizando solução de água e detergente, produtos enzimáticos e outros acessórios ${ }^{1,4,5}$.

Os detergentes utilizados no processamento dos PPS devem ser biodegradáveis, não abrasivos, atóxicos na diluição orientada pelo fabricante, eficazes na remoção de sujidades, ter baixa formação de espuma e boa rinsabilidade ${ }^{6-8}$. Por meio da ação de tensoativos, diminuem a tensão superficial da água e proporcionam maior contato dela com a sujidade contida no instrumental, favorecendo a remoção dos resíduos orgânicos e inorgânicos presentes no material ${ }^{1,4,6}$.

Atualmente, é amplamente recomendado que o detergente utilizado na limpeza de PPS possua ação enzimática9. A regulamentação desse produto no Brasil ocorre por meio da Resolução da Diretoria Colegiada (RDC) no 55, de 27 de novembro de 2012, da Agência Nacional de Vigilância Sanitária (ANVISA). Ela define os detergentes enzimáticos como produtos cuja formulação contém, além do tensoativo, pelo menos uma enzima hidrolítica da subclasse das proteases EC 3.4, e cuja finalidade é remover a sujidade clínica e evitar a formação de compostos insolúveis na superfície dos dispositivos ${ }^{10-12}$.

Diferente dos detergentes comuns, as formulações enzimáticas apresentam a capacidade de catalisar reações por meio da ação das enzimas. Essas atuam de maneira seletiva sobre a matéria orgânica, degradam substratos específicos, aceleram e otimizam o processo de limpeza dos PPS ${ }^{4,12,13}$. Dessa forma, são comercializadas formulações multienzimáticas com o objetivo de ampliar o espectro de ação do produto sobre as sujidades e tornar a limpeza mais efetiva ${ }^{4,11}$.

Há, ainda, disponíveis no mercado, diversas formulações de detergentes que, além de serem compostos por múltiplas enzimas, possuem diferente $\mathrm{pH}$. O valor do $\mathrm{pH}$ é uma importante característica do produto, uma vez que pode interferir na estabilidade da solução e, consequentemente, na atividade enzimática. Entretanto, não há no Brasil a determinação de um $\mathrm{pH}$ específico para esses produtos. A RDC $\mathrm{n}^{\circ} 55$, de 27 de novembro de 2012, da ANVISA apenas determina que a faixa de $\mathrm{pH}$ da solução pura e na diluição de uso deve ser informada no rótulo do detergente ${ }^{12}$.

Nota-se, porém, que para serem utilizados no processamento de PPS, são comercializados detergentes enzimáticos neutros, que possuem o $\mathrm{pH}$ igual a 7 , e detergentes alcalinos, cujo valor do $\mathrm{pH}$ varia entre 7 e $14^{14}$. No entanto, observa-se na prática clínica que, na limpeza de PPS, utiliza-se predominantemente a formulação neutra, reconhecida pela sua capacidade de preservação do instrumental. E, no caso do detergente alcalino, verifica-se que questionamentos acerca de sua utilização para limpeza dos PPS têm sido cada vez mais frequentes. No entanto, a escassez de informações acerca das indicações e das limitações bem como em relação aos potenciais danos que as diferentes faixas de $\mathrm{pH}$ podem causar aos PPS, tem gerado dúvidas que povoam a prática clínica.

Portanto, diante da existência de formulações alcalinas e enzimáticas neutras de detergentes destinados ao processamento de PPS e do escasso número de publicações que abordam esse assunto, questiona-se: Quais as indicações e limitações dos diferentes tipos de detergentes utilizados no processamento dos PPS?

\section{OBJETIVO}

Propõe-se como objetivo deste trabalho identificar estudos que abordem as indicações e limitações dos detergentes alcalino e enzimático neutro de forma a fornecer subsídios para uma análise crítica por parte dos profissionais de saúde.

\section{MÉTODO}

O método utilizado neste estudo foi o da revisão integrativa da literatura, pois essa permite reunir e sintetizar resultados de pesquisas sobre um delimitado tema ou questão, de maneira sistemática e ordenada, contribuindo para o aprofundamento do conhecimento do tema investigado ${ }^{15}$.

Para a construção da revisão integrativa foram realizadas seis etapas distintas: escolha da pergunta da pesquisa; definição dos critérios de inclusão e seleção da amostra; representação dos 
estudos selecionados em formato de quadros sinópticos; análise dos achados; interpretação dos resultados e sua apresentação ${ }^{15}$.

Definiu-se a seguinte questão norteadora: Quais as indicações e limitações dos diferentes tipos de detergentes utilizados no processamento dos PPS? Em seguida, delimitaram-se os seguintes critérios de inclusão: artigos originais, no idioma inglês ou português, que abordassem as indicações e limitações dos diferentes tipos de detergentes utilizados na limpeza dos PPS publicados no período de 2000 a 2016. Excluíram-se aqueles artigos que, embora tratassem de detergentes enzimáticos e alcalinos, não se relacionavam à limpeza dos PPS.

As publicações foram selecionadas a partir dos Descritores em Ciências da Saúde nos idiomas português e inglês apresentados a seguir: detergentes, infecção hospitalar, saneantes, detergents, cross infection, sanitizing products. Foram utilizados ainda os descritores não controlados: alcalino, controle de infecção, limpeza, enzima, enzimático, alkaline, infection control, cleaning, enzyme, enzymatic. Empregou-se todos os descritores isoladamente assim como associados pelo conector AND em todas as bases citadas.

A seleção dos artigos foi realizada por meio do Portal de Coordenação de Aperfeiçoamento de Pessoal de Nível Superior (CAPES) utilizando as bases de dados Scientific
Eletronic Library Online (SciELO), Science Direct, Scopus, Web of Science e PubMed.

A seleção inicial das publicações foi feita por meio da leitura exploratória do título e resumo/abstract dos trabalhos, o que acarretou na identificação de 11 estudos. Desses, um foi encontrado na base de dados SciELO, seis na Science Direct, dez na Scopus, sete na Web of Science e oito na PubMed. Alguns estudos foram encontrados em mais de uma base de dados. A partir da leitura analítica dos textos, foram selecionados, em conformidade com os critérios de inclusão e exclusão previamente definidos, três artigos.

Diante da escassez de resultados encontrados nas bases de dados citadas, foram realizadas, ainda, como estratégia de busca, pesquisas em conteúdo eletrônico disponibilizado por associações, indústrias e fabricantes de materiais médico-hospitalares, laboratórios e órgãos governamentais. Dessa forma, foram encontradas seis publicações. A essas publicações, somaram-se os três artigos provenientes das bases de dados, totalizando nove trabalhos a serem avaliados. A Figura 1 sintetiza o processo de busca das publicações.

Seguiu-se, portanto, com a categorização dos estudos por meio da criação de um quadro temático. Esse tinha como objetivo traçar um panorama geral dos artigos. Para a composição

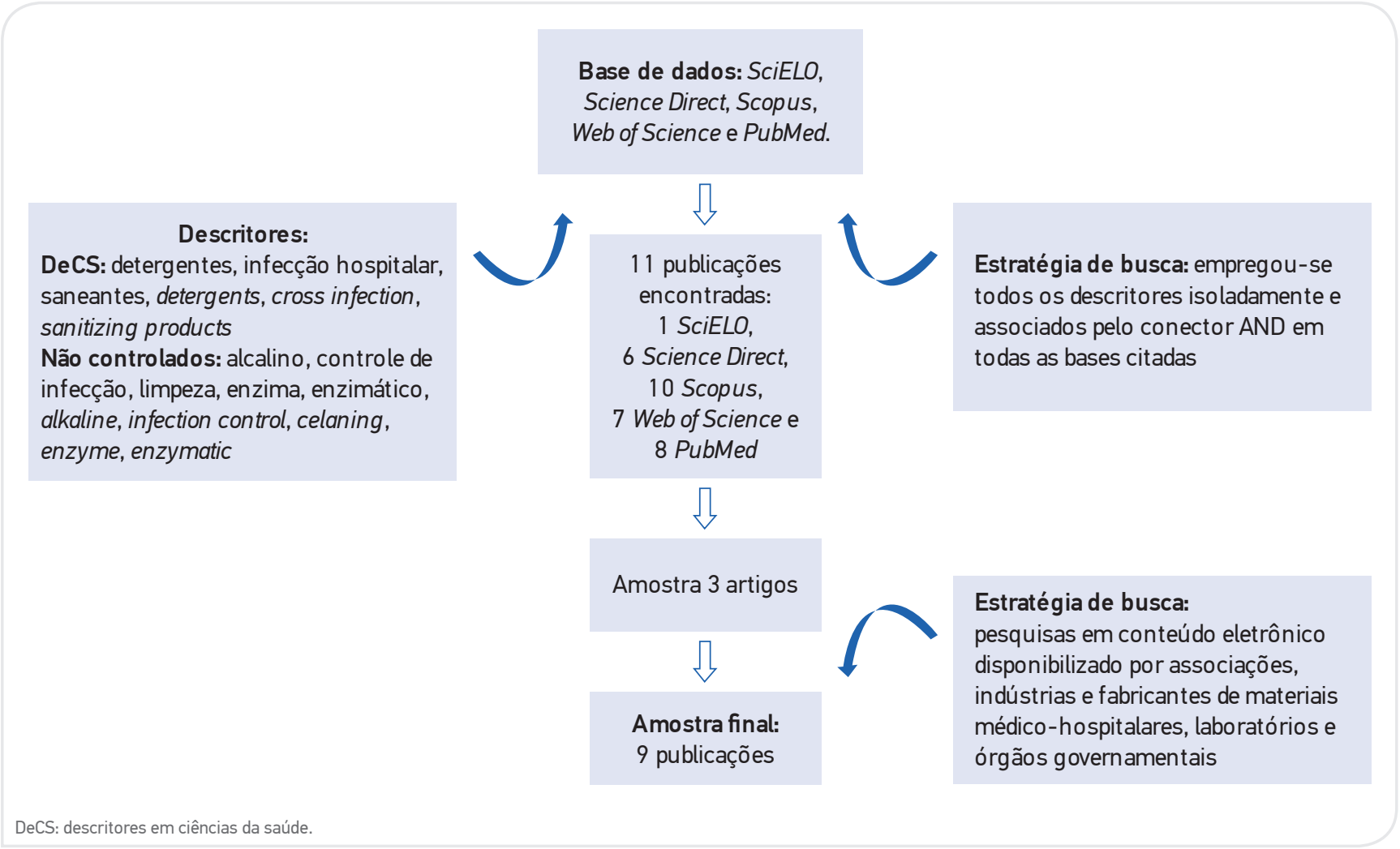

Figura 1. Processo de busca das publicações. 
do quadro temático, foram extraídas informações de cada artigo: título, autores, ano, tipo de estudo/metodologia e principais resultados. Tais informações foram apresentadas nos Gráficos 1 e 2 e no Quadro 1.

\section{RESULTADOS}

Foram identificadas nove publicações que abordaram as indicações e limitações dos detergentes alcalino e enzimático

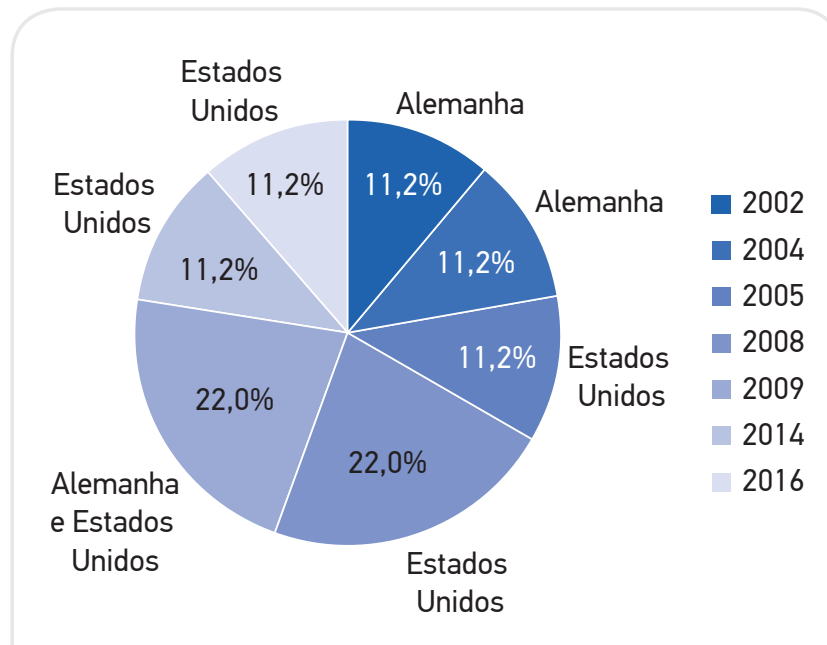

Gráfico 1. Percentual de publicações segundo o ano e país de origem, 2000 a 2016. Belo Horizonte, 2016.

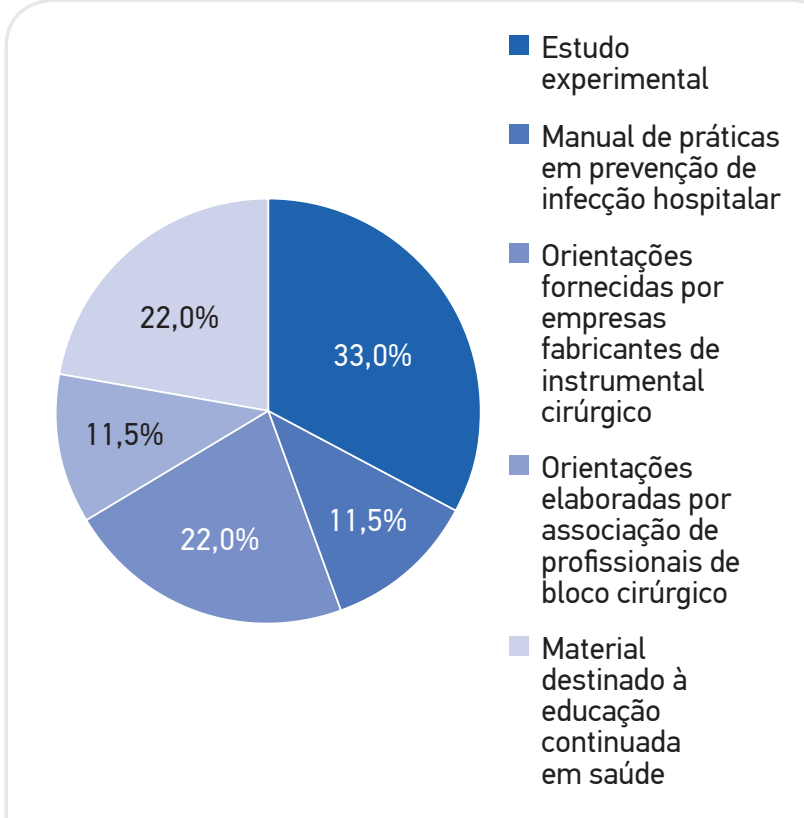

Gráfico 2. Delineamento dos estudos selecionados durante o levantamento bibliográfico (2000-2016). Belo Horizonte, 2016. neutro. Esses trabalhos foram realizados na Alemanha (22\%) e Estados Unidos (77\%). Não houve nenhum estudo realizado no Brasil para o período analisado. As publicações encontradas foram distribuídas, em relação aos anos, da seguinte forma: 2002 (11,2\%), 2004 (11,2\%), 2005 (11,2\%), 2008 (22\%), 2009 (22\%), 2014 (11,2\%), 2016 (11,2\%). Tais informações estão sintetizadas no quadro apresentado Gráfico 1.

Em relação ao delineamento dos trabalhos (Gráfico 2), foram identificadas três $(33,0 \%)$ pesquisas experimentais, um $(11,5 \%)$ manual de práticas em prevenção de infecção hospitalar, duas $(22,0 \%)$ orientações elaboradas por fabricantes de produtos médicos hospitalares, uma $(11,5 \%)$ por associação de profissionais que trabalham em bloco cirúrgico e dois (22,0\%) materiais destinados à educação continuada em saúde.

As indicações de uso dos detergentes alcalinos ${ }^{14,16-18} \mathrm{e}$ enzimáticos neutros ${ }^{5,10,14,17,19}$ empregados no processamento de PPS foram apontadas em sete estudos e as limitações do produto alcalino foram citadas em quatro publicações ${ }^{5,14,20,21}$.

Quadro 1. Indicações e limitações dos detergentes enzimáticos neutros e alcalinos utilizados na limpeza de produtos para a saúde segundo o pH. Belo Horizonte, 2016.

\begin{tabular}{|c|c|c|}
\hline \multirow[b]{2}{*}{ 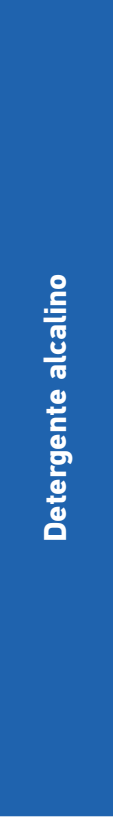 } & Indicações & $\begin{array}{l}\text { - Remoção de detritos } \\
\text { orgânicos }{ }^{10,16-18} \text {. } \\
\text { - Limpeza de PPS em processos } \\
\text { que utilizam água dura }{ }^{14} \text {. } \\
\text { - Limpeza de instrumentais } \\
\text { cirúrgicos de aço inoxidável }^{14} \text {. } \\
\text { - Limpeza em processos } \\
\text { automatizados }{ }^{14} \text {. }\end{array}$ \\
\hline & Limitações & $\begin{array}{l}\text { - Inativação das enzimas, danos } \\
\text { ao instrumental e necessidade } \\
\text { de enxágue neutralizador quando } \\
\text { elevado valor de } \mathrm{pH}^{14,20-21} \text {. } \\
\text { - Risco de causar manchas } \\
\text { no instrumental quando não } \\
\text { removido corretamente }{ }^{14,20} \text {. } \\
\text { - Risco potencial de corrosão } \\
\text { e interferência no correto } \\
\text { funcionamento do PPS } 5,14,20,21 \\
\text { - Risco de reagir com alumínio, } \\
\text { zinco, metais não ferrosos, } \\
\text { borracha e látex }{ }^{14} \text {. }\end{array}$ \\
\hline \multirow[t]{2}{*}{ 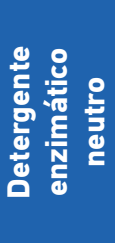 } & Indicações & $\begin{array}{l}\text { - Compatíveis com metais e outros } \\
\text { materiais utilizados nos PPS, tais } \\
\text { como alumínio, cobre, plástico e } \\
\text { borracha }{ }^{5,10,14} \text {. } \\
\text { - Não danifica o PPS } 5,14,17,19 \text {. }\end{array}$ \\
\hline & Limitações & - Não foram encontradas. \\
\hline
\end{tabular}

PPS: produtos para a saúde. 
Não foram encontradas limitações relacionadas à utilização de detergente enzimático neutro na limpeza dos PPS. A sinopse desses achados encontra-se no Quadro 1.

Os estudos apontaram que os detergentes alcalinos são apropriados para limpeza de instrumentais cirúrgicos fabricados em aço inoxidável e proporcionam eficaz remoção de gorduras, proteínas e demais resíduos orgânicos, desagregando-os do PPS mais facilmente, quando comparados ao detergente neutro ${ }^{14,16-18}$. Em processos de limpeza em que é utilizada água dura (quando há presença de íons de metais alcalino-terrosos na água), o produto alcalino é o mais indicado para ser empregado ${ }^{14}$.

Os detergentes alcalinos podem danificar os PPS, uma vez que são capazes de manchá-los e corroê-los causando interferência no correto funcionamento dos dispositivos ${ }^{20,21}$. Esses danos podem acontecer caso o detergente não seja removido corretamente dos instrumentais durante o enxágue, se utilizados em determinados materiais, tais como alumínio, zinco, metais não ferrosos, borracha e látex e quando a formulação apresentar elevado valor de $\mathrm{pH}$ (acima de 12), fazendo-se necessário, nesse caso, a utilização de um produto neutralizador, a fim de evitar maiores danos aos dispositivos $^{14}$. O enxágue neutralizador acontece com a adição de uma solução ácida à água, com o objetivo de diminuir o pH da solução, tornando-a com valores próximos à neutralidade ${ }^{14}$. $\mathrm{O}$ pH acima de 12 pode ainda prejudicar a ação das enzimas à medida que diminui a funcionalidade dessas substâncias ${ }^{14}$.

Os detergentes enzimáticos neutros possuem melhor perfil de compatibilidade com diferentes materiais, tais como alumínio, metais não ferrosos e borracha proporcionam melhor desempenho das enzimas, não corroem o instrumental cirúrgico e não danificam os PPS. Eles são utilizados para auxiliar o desprendimento da matéria orgânica presente na superfície do intrumental ${ }^{5,14,17,19}$.

\section{DISCUSSÃO}

O potencial de ação das enzimas presentes no detergente enzimático é influenciado por uma série de fatores, dentre eles o pH da formulação. Variações de $\mathrm{pH}$ para valores acima ou abaixo do necessário para que a atividade enzimática ocorra de forma satisfatória pode inativá-las e interferir na ação dessas substâncias. Esse valor é determinado de acordo com a natureza das enzimas presentes no detergente, uma vez que cada uma delas apresenta um pH ótimo de atuação que permite o desempenho máximo da atividade exercida por ela ${ }^{13,22}$. Os detergentes enzimáticos não possuem propriedade bactericida para destruir microrganismos, mas para eliminar a matéria orgânica que serve como substrato para que os microrganismos se multipliquem ${ }^{23}$.

De acordo com a RDC n ${ }^{\circ}$ 55, de 27 de novembro de 2012, da ANVISA, as formulações enzimáticas não podem conter substâncias que comprometam a atividade das enzimas ou que danifiquem os materiais e equipamentos que entrem em contato com esses produtos ${ }^{1}$. Dessa maneira, o detergente enzimático neutro foi indicado como o que apresenta melhor perfil de compatibilidade com os materiais que compõem os PPS, não tendo sido relatado, na biografia estudada, danos que essa solução possa causar a esses dispositivos ${ }^{5,14,17,19}$.

Em contrapartida, o produto alcalino foi apontado como compatível com dispositivos produzidos em aço inoxidável, mas incompatível com vários outros materiais que estão presentes na composição de diversos PPS, incluindo alumínio, zinco, metais não ferrosos, borracha e látex ${ }^{14}$. A compatibilidade do aço inoxidável ao detergente alcalino é decorrente da presença de uma camada de óxido de cromo $\left(\mathrm{Cr}_{2} \mathrm{O}_{2}\right)$ na superfície do material, formada de maneira passiva por meio da reação do oxigênio com o cromo presente na superfície do material. Essa camada confere extrema resistência à corrosão, protegendo o aço dos danos que a formulação alcalina poderia causar, da ação de muitos produtos químicos e de parâmetros físicos, tais como variações de temperatura e de $\mathrm{pH}^{24,25}$.

Os PPS não compatíveis com detergente alcalino podem ser manchados, corroídos e sofrer interferência no correto funcionamento quando em contato com o produto ${ }^{5,14,20,21}$. Esses danos que ocorrem nos dispositivos implicam em maiores custos ao serviço de saúde, uma vez que esses locais terão, adicionados ao orçamento, gastos com manutenção e substituição de instrumentais.

Em relação ao potencial de ação dos detergentes, algumas publicações indicaram a formulação alcalina como a mais eficaz na remoção de matéria orgânica ${ }^{16-18}$. Um estudo desenvolvido por Smith et al. ${ }^{26}$ corrobora essa afirmativa. O experimento realizado consistiu na avaliação da ação de diferentes produtos químicos, incluindo detergentes alcalino e neutro, na remoção de sangue de cavalo impregnado em placas de aço inoxidável. As placas de metal foram inoculadas junto ao produto de limpeza a ser testado e agitadas em plataforma de agitação. O tempo de exposição e a temperatura da solução foram os mesmos para todas as soluções testadas. Ao término do procedimento, o pesquisador encontrou, por meio do ensaio de ácido bicinconínico — método de quantificação de proteínas compatível com detergentes e agentes desnaturantes $^{27}$ - melhor eficácia do detergente alcalino na remoção das proteínas presentes na superfície das placas de metal ${ }^{26}$. 
Em outro estudo, desenvolvido por um fabricante de produtos utilizados no processamento de PPS, comparouse o desempenho de diversos detergentes empregados na limpeza desses dispositivos, sendo eles: detergente alcalino, alcalino com enzimas e multienzimáticos com pH neutro. Plaquetas de metal foram preparadas com diferentes sujidades que incluíam: sangue iodado; sangue coagulado; lipídio enriquecido com proteínas; polissacarídeos; proteínas e polissacarídeo. Em seguida, foram embebidas em solução de limpeza e agitadas em agitador. No final do tempo de contato estabelecido, as amostras foram removidas da solução, enxaguadas em água fria, secadas e examinadas visualmente. Concluiu-se que, na remoção das sujidades impregnadas em plaquetas de metal, os produtos enzimáticos neutros foram os que apresentaram os piores resultados; e as formulações alcalinas foram as que apresentaram melhor eficácia ${ }^{28}$.

Porém, resultado divergente apontou que, em termos de efetividade, não há diferença significativa entre os detergentes enzimáticos neutro e alcalino ${ }^{17}$. Tal achado foi encontrado por Zuhlsdorf ${ }^{17}$ em um experimento que consistiu na inoculação de sangue contendo Enterococcus faecium em tubos de teflon, que em seguida foram submetidos à limpeza automatizada com a utilização dos diferentes agentes de limpeza. A eficácia do processo foi avaliada visualmente e microbiologicamente por meio de contagem bacteriana ${ }^{17}$.

Na prática clínica, os profissionais têm notado uma aparente superioridade do desempenho dos detergentes alcalinos, uma vez que os PPS, ao serem processados com tal produto, adquirem maior brilho e melhor aspecto à medida que essas formulações realizam uma limpeza profunda no instrumental, removendo incrustações em sua superfície.

Assim, as formulações alcalinas têm sido padronizadas na rotina de trabalho de alguns serviços de saúde, embora sejam escassos os referenciais sobre o tema e muitos profissionais ainda não possuam o real conhecimento acerca da ação do produto. O uso dessas formulações requer cautela, uma vez que esse tipo de detergente necessita que haja um controle rigoroso do enxágue, da temperatura da solução, do $\mathrm{pH}$ da água, além de não possuir compatibilidade com todo tipo de material, sob pena de causar danos irreversíveis no PPS e prejudicar a eficácia do processamento dos dispositivos.

Embora o valor comercializado desse produto seja, em geral, superior ao do detergente enzimático, os fabricantes prometem maior rentabilidade da formulação, fazendo com que seja mais econômico. Entretanto, há de se avaliar o desgaste do material e os custos com reparo e substituição.
As formulações alcalinas, em geral, são indicadas pelos fabricantes para serem utilizadas em processos automatizados de limpeza (lavadoras termodesinfetadoras e ultrassônicas) devido à baixa formação de espuma. Essa é uma característica necessária nesse método de processamento, uma vez que previne danos aos equipamentos ao diminuir o tempo do ciclo de limpeza devido ao menor tempo de enxágue e ao causar menores danos à bomba de recirculação $0^{29,30}$.

Embora a formação de espuma por parte do detergente alcalino seja menor, essa propriedade deve ser observada também na escolha do detergente a ser utilizado na limpeza realizada de forma manual. A pouca formação de espuma proporciona maior segurança do profissional ao aumentar a visibilidade de instrumentais cortantes dentro da solução e otimizar o processo de limpeza à medida que facilita o enxágue e a visualização de sujidades no instrumental ${ }^{14}$.

Ser compatível com equipamentos utilizados no processamento automatizado é uma vantagem do produto, visto que esse tem sido considerado o método ideal de limpeza. Quando comparado com o método manual, o processo automatizado tem se demonstrado mais significativo em termos de redução da carga microbiana nos PPS $^{31-33}$.

Podem ser listados ainda como vantagem desse método, a diminuição de riscos ocupacionais, pois restringe o contato do profissional com o material contaminado; a padronização do processo, uma vez que se espera que em todos os diferentes ciclos de limpeza o equipamento funcione de maneira igual; e a capacidade de mensurar e documentar os parâmetros envolvidos no processamento, como por exemplo o tempo e a temperatura da solução.

Contudo, há de se atentar a outras características do detergente, seja neutro ou alcalino, quando utilizados no processamento dos PPS, independentemente do método adotado. É preciso estar atento ao fato de que a contaminação bacteriana pode estar presente em soluções de limpeza contidas em lavadora ultrassônica ou em recipientes de limpeza manual, uma vez que detergentes enzimáticos normalmente não possuem ação bactericida ${ }^{21}$.

O ideal para que tal contaminação não ocorra é que haja o descarte da solução de limpeza a cada utilização, conforme orientado no Guideline for Disinfection and Sterilization in Health-care Facilities, 2008, do Centers for Disease Control and Prevention 5 . Porém, na prática clínica, o que se observa são soluções de detergentes enzimáticos reutilizadas por diversas vezes, contrariando tal informação. Nesse cenário, o descarte desses produtos é, em geral, determinado pelos profissionais por meio de métodos subjetivos de avaliação da qualidade 
da solução, como por exemplo, presença de sujidade visível ou turvação. Essa prática de reutilização do detergente enzimático é exercida pelos serviços de saúde para diminuir custos no processamento dos materiais em detrimento da segurança do processo, ainda que estudos apontem que o reuso da solução de detergente enzimático pode contribuir para a elevação da carga microbiana nos PPS nela imersos ${ }^{34}$.

Outro aspecto importante a ser analisado, para que durante o processamento dos PPS o detergente seja empregado de maneira correta, refere-se às características da água utilizada. Em processos de limpeza em que a água dura está presente, o detergente alcalino é o mais adequado para ser aplicado $^{14,35}$. A água dura possui elevada quantidade de sais de metais alcalino-terrosos (cálcio, magnésio e estrôncio), que se desprendem da solução e se depositam na superfície do PPS quando a água é aquecida ou evaporada, o que prejudica a ação da maior parte dos detergentes e desinfetantes. Nesse processo, os íons liberados interagem com alguns produtos químicos e formam precipitados insolúveis na superfície do instrumental, podendo causar corrosões e manchas nos dispositivos ${ }^{36,37}$.

A água é o elemento mais amplamente utilizado em todo o processo de limpeza dos PPS e por isso requer atenção?. No Brasil, a água utilizada no processamento de PPS deve atender aos padrões de potabilidade definidos em normatização específica, a Portaria ${ }^{\circ}$ 2914, de 12 de dezembro de 2011, do Ministério da Saúde ${ }^{35}$. Quando ela não atende aos requisitos adequados, alguns processos para tratá-la podem ser utilizados. Os sistemas de destilação ou desmineralização, por exemplo, removem praticamente todo o material iônico nela dissolvido, transformando-a em água mole ${ }^{37}$. Sabe-se, portanto, que a água dura não é indicada para ser utilizada em serviços de saúde, sendo sua utilização, portanto, irregular.

\section{CONCLUSÃO}

Por se tratar de uma revisão de literatura, devem-se ponderar as limitações que os resultados encontrados guardam em si, uma vez que há a abrangência das estratégias adotadas, bem como dos descritores definidos. Isso por si só abre um leque de oportunidades para o investimento em outros estudos que abordem o tema.

Somado a esse fato, encontrou-se como importante limitação deste estudo o fato das indicações e limitações dos detergentes utilizados no processo de limpeza dos PPS ainda serem um assunto pouco explorando na literatura científica, o que contribuiu para que fosse selecionado reduzido número de artigos.

O detergente alcalino é um produto relativamente novo no mercado brasileiro e precisa ter suas características exploradas e conhecidas antes de serimplementado nos serviços de saúde, uma vez que, embora apresente características de destaque, como o desempenho de uma limpeza profunda no PPS, a sua utilização possa causar danos irreversíveis aos dispositivos. Nesse aspecto, a compatibilidade do detergente enzimático neutro com diferentes tipos de materiais é uma vantagem desempenhada por essa formulação, à medida que reduz gastos com manutenção e aquisição de novos PPS.

De acordo com as características apresentadas, tanto o produto enzimático neutro como o alcalino apresentam indicações e limitações específicas que devem ser observadas pelos profissionais antes de padronizá-los para a limpeza do PPS.

Embora tenham sido encontrados na literatura registros de que o detergente alcalino apresenta um melhor desempenho em relação à limpeza dos PPS, resultados divergentes também foram verificados, o que torna necessária a condução de mais estudos clínicos sobre o tema.

\section{REFERÊNCIAS}

1. Brasil. Ministério da Saúde. Resolução da Diretoria Colegiada (RDC) n. ${ }^{\circ} 15$, de 15 de março de 2012. Dispõe sobre os requisitos de boas práticas para o processamento de produtos para saúde e dá outras providencias. Diário Oficial da União, Brasília, 2012 [acesso em 28 set. 2016]. Disponível em: <http://www.sobecc.org.br/ arquivos/legislacao/06\%20RESOLU\%C3\%87\%C3\%830_RDC_\%20 N\%C2\%BA15_ANVISA_\%20MAR\%C3\%870\%202012.pdf>

2. Association of Operative Registered Nurses. AORN Guidance Statement: Reuse of Single-Use Devices. AORN Journal. 2006 [acesso em 9 set.
2016];84(5):876-84. Disponivel em: <http://www.ascquality.org/Library/ singleusedevicereprocessingtoolkit/AORN\%20Guidance\%20Statement\%20 on $\% 20$ Reuse $\% 20$ of $\% 20$ Single $\% 20$ Use $\% 20$ Devices $\% 202006$.pdf>

3. RazakS, Yee R. Medical device reuse: the return of Robin Hood? Heart Rhythm. 2010;7(11):1628-29. DOI: 10.1016/j.hrthm.2010.09.014

4. Graziano KU. Considerações sobre uso de detergente enzimáticos no processo de limpeza: revisão de literatura. Rev SOBECC. 2002;7(4):18-21. 
5. Centers for Disease Control and Prevention. Guideline for disinfection and sterilization in health-care facilities. Atlanta: CDC; 2008 [acesso em 1. ${ }^{\circ}$ ago. 2016]. Disponível em: <https://www.cdc.gov/hai/pdfs/ disinfection_nov_2008.pdf>

6. Shoemake S, Stoessel K. Cleaning Reusable Medical Devices: a Critical First Step. Clinical Issue. 2007 [acesso em 8 set. 2016]:11. Disponível em: <http://pt.halyardhealth.com/media/1514/cleaning_ reusable_devices.pdf $>$

7. International Association for Soaps, Detergents, and Maintenance Products. Guidelines on the implementation of the Detergents Regulation. 2013 [acesso em 10 ago. 2016];2. Disponível em: <https:// www.aise.eu/cust/documentrequest.aspx?DoclD=234>

8. Association of Operative Registered Nurses. Guideline Summary: Cleaning and Care of Surgical Instruments. AORN Journal. 2015;101(5):553-7. DOl: http://dx.doi.org/10.1016/j.aorn.2015.01.001

9. Brasil. Ministério da Saúde. Agência Nacional de Vigilância Sanitária. Informe técnico n. 0 01/09 - Princípios Básicos para Limpeza de Instrumental Cirúrgico em Serviços de Saúde. Brasília, fev. 2009 [acesso em 1. ${ }^{\circ}$ ago. 2016]. Disponível em: <http://www.anvisa.gov. br/servicosaude/controle/alertas/2009/informe_tecnico_1.pdf>

10. Root CW, Kaiser N, Antonucci C. What, how and why: enzymatic instrument cleaning products in healthcare environments. Healthcare Purchasing News. 2008 [acesso em 27 ago. 2016]:50-4. Disponível em: <http://www.hpnonline.com/ce/pdfs/0811 cetest.pdf>

11. Beilenhoff U, Neumann CS, Rey JF, Biering H, Blum R, Cimbro M, et al. ESGE-ESGENA guideline: cleaning and disinfect in gastrointestinal endoscopy. Endoscopy. 2008;40(11):939-57.

12. Brasil. Ministério da Saúde. Resolução da Diretoria Colegiada (RDC) n. ${ }^{\circ} 55$, de 14 de novembro de 2012. Dispõe sobre os detergentes enzimáticos de uso restrito em estabelecimentos de assistência à saúde com indicação para limpeza de dispositivos médicos e dá outras providências. Diário Oficial da União. 2012 [acesso em 1. ${ }^{\circ}$ ago. 2016]. Disponível em: <http://bvsms.saude.gov.br/bvs/saudelegis/ anvisa/2012/rdc0055_14_11_2012.pdf>

13. Society of Gastroenterology Nurses and Associates. Standards of Infection Control in Reprocessing of Flexible Gastrointestinal Endoscopes. 2012 [acesso em 14 mar. 2017]. Disponível em: <https:// www.sgna.org/Portals/0/Education/PDF/Standards-Guidelines/ sgna_stand_of_infection_control_0812_FINAL.pdf

14. Pfiedler Enterprise. The Role of Detergents and Disinfectants in Instrument Cleaning and Reprocessing. 2014 [acesso em 5 ago. 2016]. Disponível em: http://www.pfiedler.com/ast/1196a/files/ assets/common/downloads/The $\% 20$ Role $\% 20$ of $\% 20$ Detergents $\% 20$ and $\% 20$ Disinfectants $\% 20 \mathrm{in} \% 20$ Instrument $\% 20$ Cleaning $\% 20$ and $\% 20$ Reprocessing\%20-\%20AST.pdf

15. Mendes KDS, Silveira RCCP, Galvão CM. Revisão integrativa: método de pesquisa para a incorporação de evidências na saúde e na enfermagem. Texto Contexto Enferm. 2008;17(4):758-64.

16. Zuhlsdorf B, Floss H, Martiny H. Cleaning efficacy of nine different cleaners in a washer-disinfector designed for flexible endoscopes. J Hosp Infect. 2002;52(3):206-11. DOI: 10.1053/jhin.2002.1284

17. Zuhlsdorf B, Floss H, Martiny H. Efficacy of 10 different cleaning processes in a washer-disinfector for flexible endoscopes. J Hosp Infect. 2004;56(4):305-11. DOI: 10.1016/j.jhin.2004.01.001
18. Association of Surgical Technologists. Standards of Practice for the Decontamination of Surgical Instruments. 2009 [acesso em 6 ago. 2016]. Disponível em: http://www.ast.org/uploadedFiles/Main_Site/Content/ About_Us/Standard_Decontamination_\%20Surgical_Instruments_.pdf

19. Hutchisson B, Leblanc C. The Truth and Consequences of Enzymatic Detergents. Gastroenterol Nurs. 2005;28(5):372-6.

20. Roboz Surgical Instrument. Cleaning, Sterilization \& Maintenance of Surgical Instruments. 165-66. [acesso em 6 ago. 2016]. Disponível em: http://www.roboz.com/catalog\%20pdfs/sterilization_and_ maintenance.pdf

21. Sharn Inc. Anesthesia. Official Guide: Maintaining \& Cleaning Surgical Instruments. 2009 [acesso em 6 ago. 2016]. Disponível em: http:// www.sharn.com/images/art/Maintaining-and-Cleaning-SurgicalInstruments.pdf

22. Olsen HS, Falholt P. The Role of Enzymes in Modern Detergency. J Surfact Deterg. 1998;1(4):555-67. DOI: 10.1007/s11743-998-0058-7

23. American Society for Gastrointestinal Endoscopy. Multisociety guideline on reprocessing flexible gastrointestinal endoscopes: 2011. Gastrointestinal Endoscopy. 2011 [acesso em 16 set. 2016];73(6). Disponível em: https://www.sgna.org/Portals/0/Education/PDF/ Standards-Guidelines/10_multisocietyguideline_2011.pdf

24. Mariano SFM, Santos AL, Ueda M, Oliveira RM. Análise das propriedades superficiais do aço inoxidável ABNT 304 modificado por implantação iônica por imersão em plasma de nitrogênio em alta temperatura. Rev Bras Aplicações Vácuo. 2011 [acesso em 15 set. 2016];30(12):24-9. Disponível em: http://www.sbvacuo.org.br/rbav/index.php/ rbav/article/view/955

25. Buss GAM, Donath KS, Vicente MG. Utilização de aços inoxidáveis em implantes. Boletim Informativo de Tecnovigilância, Brasília, Número Especial, dez. 2011 [acesso em 6 mar. 2017]. Disponível em: http://www. anvisa.gov.br/boletim_tecno/boletim_tecno_dezembro_ed_especial/ PDF/1-Utiliza\%E7\%E3o\%20de\%20a\%E7os\%20inoxid\%E1 veis\%20 em\%20implantes.pdf

26. Smith WG, McNeil J, Ramage G, Smith AJ. In vitro evaluation of cleaning efficacy of detergents recommended for use on dental instruments. Am J Infect Control. 2012;40(9):255-9. DOI: 10.1016/j. ajic.2012.05.009

27. Johnson M. Protein Quantitation. Materials and Methods. 2012 [acesso em 14 mar. 2017];2:115. Disponível em: https://www.labome.com/ method/Protein-Quantitation.html

28. Dr. Weigert. Demonstrando a Eficácia de Limpeza de Diferentes Tipos de Detergentes para Limpeza Manual de Dispositivos Médicos. 2005 [acesso em 3 set. 2016]. Disponível em: http://www.humansp.med. br/arquivos_dados/foto_alta/foto-educa-id-33.pdf

29. Kauffman M, Joseph C. Ultrasonic cleaning in the healthcare setting. Healthcare Purchasing News. 2011 [acesso em 10 set. 2016]. Disponivel em: http://www.hpnonline.com/ce/pdfs/1101 cestest.pdf

30. Labnews Soluções de Limpeza e Desinfecção [Internet]. Detergente alcalino. 2013 [acesso em 5 set. 2016]. Disponível em: http://www. labnews.ind.br/produtos/detergente-alcalino.html

31. Alfa MJ, Olson N, Al-Fadhaly A. Cleaning efficacy of medical device washers in North American healthcare facilities. J Hosp Infect. 2010;74(2):168-77. DOI: 10.1016/j.jhin.2009.06.030 
32. Alfa MJ. Monitoring and improving the effectiveness of cleaning medical and surgical devices. Am J Infect Control. 2013;41:S56-9. DOI: 10.1016/j.ajic.2012.12.006

33. British Columbia Health Authorities. Best Practice Guidelines for Cleaning, Disinfection and Sterilization of Critical and Semi-critical Medical Devices. 2011 [acesso em 6 set. 2016]. Disponível em: http:// www.health.gov.bc.ca/library/publications/year/2011/Best-practiceguidelines-cleaning.pdf

34. Evangelista SS, Santos SG, Stoianoff MAR, Oliveira AC. Analysis of microbial load on surgical instruments after clinical use and following manual and automated cleaning. Am J Infect Control. 2014;43(5):5227. DOI: 10.1016/j.ajic.2014.12.018

35. Brasil. Ministério da Saúde. Portaria n. ${ }^{\circ} 2.914$, de 12 de dezembro de 2011. Dispõe sobre os procedimentos de controle e de vigilância da qualidade da água para consumo humano e seu padrão de potabilidade. Diário Oficial da União. 2011 [acesso em 8 set. 2016]. Disponivel em: http://bvsms.saude.gov.br/bvs/saudelegis/gm/2011/ prt2914_12_12_2011.html

3.. Center for Healthcare Related Infection Surveillance and Prevention. Disinfection \& Sterilization: Infection Control Guidelines. 2008 Nov [acesso em 8 set. 2016]. Disponivel em: https://www.health.qld.gov. au/chrisp/sterilising/large_document.pdf

37. NHS Wales Shared Services Partnership - Facilities Services. Department of Health. Welsh Health Technical Memorandum 01-01: decontamination of medical devices within acute services. Part B: Common elements. Department of Health. England: NHS Wales Services Partnership; 2013. 37p. [acesso em 8 set. 2016]. Disponível em: http://www.wales.nhs.uk/sites3/Documents/254/WHTM\%20 01-01\%20Part\%20B.pdf 